Bull. Egypt. Soc. Physiol. Sci. 40 (2), 54-69

\author{
Bull. of Egyp. Soc. Physiol. Sci. \\ (Official Journal of Egyptian Society for Physiological Sciences) \\ (pISSN: 1110-0842; eISSN: 2356-9514)
}

\title{
Maternal Metabolic Alterations in Monosodium Glutamate Fed Rats during Gestation and Lactation Period
}

\author{
Doaa A. Abou-Bakr ${ }^{1}$, Rania S. A. E. Mansour ${ }^{1}$ \\ ${ }^{1}$ Physiology Department, Faculty of Medicine, Ain Shams University, Egypt
}

Received: 29 Dec 2019

Accepted: 30 Jan 2020

Available online: 1 July 2020

\section{Keywords}

- MSG

- Pregnancy

- Lactation

- Metabolism

- Pancreatic function

\section{Abstract}

Background: Monosodium glutamate (MSG), an extensively used food additive, is claimed to cause many health problems, its use is still under debate. Aim: to explore the metabolic and hypertensive effect of MSG dietary administration in pregnant and lactating female rats, and its possible underlying mechanism. Methods: 16 adult female albino Wister rats were allocated into 2 groups, control group; were fed standard rat chow, and MSG group; were fed 2\% MSG supplemented rat chow throughout gestation and lactation period. Oral glucose tolerance test (OGTT) and arterial blood pressure (ABP) were measured at mid and late gestation, mid and late lactation periods. At mid lactation period, a retroorbital samples were analyzed for fasting glucose, lipid profile; triglycerides (TGs), total cholesterol (TC), high density lipoprotein-cholesterol (HDL-C), and low density lipoprotein-cholesterol (LDL-C), hormonal assays; insulin, glucagon, prolactin, corticosterone and $\mathrm{ACTH}$, as well as pancreatic lipase, amylase and malondialdehyde (MDA). By the end of lactation, adipose tissue was assessed for glucose transporter-4 (GLUT-4) and hormone sensitive lipase (HSL) relative expression. Results: MSG rats showed elevated ABP during pregnancy and lactation, with impaired OGTT at mid and late lactation period. Fasting serum glucose, TGs, TC, LDL-C, glucagon, corticosterone, pancreatic lipase and amylase, MDA as well as adipose tissue HSL expression were significantly elevated, while, fasting serum insulin, ACTH and adipose tissue GLUT-4 expression were significantly declined in MSG fed rats as compared to control group. Conclusion: MSG feeding during pregnancy and lactation induced hypertension and metabolic alterations that could be due to pancreatic and adrenal affection secondary to oxidative stress. 


\section{INTRODUCTION}

Monosodium glutamate (MSG) is a flavoring substance, used extensively in industrialized food. Its production is increased reflecting its ample use in the food industry (1). Short-term transient intake of high doses of MSG is claimed to cause several health problems, however, the effects of regular MSG dietary use is more important and still under high scientific debate (2).

Kazmi et al. (3) showed that MSG intake could lead to induction of obesity, diabetes, hepatotoxicity, neurotoxicity, and genotoxicity. The metabolic dysfunction related to MSG intake had been characterized by hyperglycemia, hypertriglyceridemia, hyperinsulinemia, hyperleptinemia, these adverse effects were attributed to the oxidant and antioxidant imbalance even in the absence of obesity(4).

Maintaining glucose homeostasis needs hormonal and neuronal integration, the hypothalamic-pituitary-adrenal (HPA) axis is extensively involved, boosting hepatic glycogenolysis and gluconeogenesis

Glutamate is an excitatory neurotransmitter, and its $\mathrm{N}$-methyl D-aspartate (NMDA) receptors are widely distributed in the brain regulating numerous necessary metabolic and autonomic activities (6).

Leshchenko et al. (7) recommended to reconsider the maximum accepted dose of MSG because of its pancreatic adverse effect, where the histopathological changes after its prolonged administration were characteristic of acute pancreatitis.
Gestational diabetes and hypertension are the commonest health problems associated with pregnancy that have negative maternal and fetal outcomes $(8,9)$.

It was reported that MSG could induce hypertension in pregnant rats (10). However experimental data concerning the maternal adverse effects of MSG are deficient compared to off springs.

So, we aimed to investigate the metabolic and hypertensive effect of MSG dietary administration in pregnant and lactating female rats.

\section{Materials and methods:}

This experiment was conducted on 16 female albino Wister rats weighing $170-200 \mathrm{~g}$. at the start of the study. Rats were obtained from the VACSERA and maintained in Medical Ain Shams Research Institute (MASRI) under standard conditions of boarding. Rats were fed regular diet composed of bread, milk and vegetables, and water ad libitum. All procedures on animals were confirmed by Ain Shams university ethical committee. Unnecessary pain and stress during animal manipulation were avoided. At the end of experiment, animals were killed by overdose of anesthesia. Animal remains disposal occurred by incineration.

\section{Experimental Procedure:}

After the two weeks acclimatization period, half of the female rats started feeding with $2 \%$ Monosodium glutamate (MSG) supplemented rat chow as described by Boutry et al. (11) for a week then breeding was succeeded with the ratio of 1 male / 3 females in a cage, vaginal smear was done each morning, sperm positive smears were considered as 
the zero day of pregnancy. MSG was purchased from Sigma-Aldrich, 2 g. of MSG was added to 98 g. rat chow to prepare $2 \%$ MSG supplemented rat chow.

Then, rats were allocated into two groups; Control group $(\mathrm{n}=8)$; pregnant rats received commercial rat chow throughout their pregnancy and lactation period (6 weeks) and Monosodium glutamate (MSG) group $(n=8)$; pregnant rats received $2 \%$ MSG supplemented rat chow throughout the experimental period. Late pregnant rats were housed in a separate cage until labor and throughout their lactation period. All rats were subjected to estimation of the initial and final body weight and the number of off springs, as well as, the following measures during the study period:

- Measurement of arterial blood pressure (ABP): systolic, diastolic and mean arterial pressure (SBP, DBP and MAP) were measured twice during pregnancy (mid and late pregnancy, on the $8^{\text {th }}-10^{\text {th }}$ and $18^{\text {th }}-20^{\text {th }}$ day of pregnancy, respectively) and twice during lactation (mid and late lactation, on the $8^{\text {th }}-10^{\text {th }}$ and $18^{\text {th }}-20^{\text {th }}$ day of lactation, respectively) using the noninvasive small animal tail blood pressure system (NIBP200A, Biopac systems Inc; USA).

- Oral glucose tolerance test (OGTT): was assessed twice during pregnancy (mid and late pregnancy) and twice during lactation (mid and late lactation), a rat tail blood sample was used to measure fasting blood glucose, then rats received $2 \mathrm{~g} / \mathrm{kg}$ glucose solution by oral gavage, followed by blood glucose level measurement at 30, 60, 90 and 120 minutes, using blood glucose meter (ACCU-CHEK Active).

At mid lactation period, a retroorbital blood sample was collected, centrifuged for serum separation for later determination of fasting glucose, lipid profile, insulin, glucagon, pancreatic lipase and amylase, corticosterone, ACTH, prolactin, as well as, malondialdehyde (MDA).

After the end of the lactation period, overnight fasted rats were weighed and anaesthetized intraperitoneally by pentobarbital in a dose of $40 \mathrm{mg} / \mathrm{kg}$ body weight, abdominal fat pads (retroperitoneal) were excised for later assessment of glucose transporter-4 (GLUT-4) and hormone sensitive lipase (HSL) relative expression.

Serum glucose was colorimetrically determined using BioMed-Glucose L.S, supplied by BIOMED DIAGNOSTICS. Total Cholesterol (TC), Triglycerides (TGs), and High-density lipoprotein cholesterol (HDL-C) were quantitatively assessed colorimetrically using kits supplied by Biodiagnostic. Low density lipoprotein cholesterol LDL-C was calculated according to Friedewald (12): LDL-C $=\mathrm{TC}-$ HDL-C - (TGs/5). Serum malondialdehyde (MDA) was estimated colorimetrically using kits supplied by Biodiagnostic.

Serum insulin, glucagon were determined by using rat specific ELISA kit applying the quantitative sandwich enzyme immunoassay technique supplied by MyBioSource and CUSABIO, respectively. Exocrine pancreatic function was assessed by serum amylase and lipase activity colorimetric assay using kits supplied by BioVision and Abonova, respectively. Serum prolactin was estimated using rat prolactin ELISA kit employing quantitative immunoassay supplied by MyBioSource. Determination of serum adrenocorticotrophic hormone (ACTH) and corticosterone using rat specific ELISA kit 
employing the competitive enzyme immunoassay technique supplied by CUSABIO.

Gene expression of adipose tissue glucose transporter-4 (GLUT-4) and hormone sensitive lipase (HSL) were analyzed quantitatively using real-time polymerase chain reaction (PCR); total RNA was extracted from tissue homogenate of adipose tissue, complementary DNA was synthesized using SuperScript III First-Strand Synthesis System. Real time PCR amplification and analysis were performed using an applied Biosystem with software version 3.1 (StepOne $^{\mathrm{TM}}$, USA). The used GLUT-4 forward primer was 5'GAGCCTGAATGCTAATGGAG-3', and the reverse primer was 5'GAGAGAGAGCGTCCAATGTC-3'. The HSL forward primer was $5^{\prime}$ GGCTTACTGGGCACAGATACCT-3', the reverse primer was 5' CTGAAGGCTCTGAGTTGCTCAA-3'. Beta actin was used as a control housekeeping gene, its forward primer was 5'GGTCGGTGTGAACGGATTTGG-3', the reverse primer was $5^{\prime}$ ATGTAGGCCATGAGGTCCACC-3'.

\section{- Calculation of the area under the curve of oral} glucose tolerance test (OGTT): First, the area under the curve between two times ( $\mathrm{t} 1$ and $\mathrm{t} 2$ ) was calculated as being the product of the time difference multiplied by the average of the two measurements ( $\mathrm{y} 1$ and $\mathrm{y} 2$ ), as follows; [t2-tl] $[(\mathrm{y} 1+\mathrm{y} 2 / 2)]$. Then, the total area under the curve was calculated by summation of the areas under the graph between each pair of consecutive observations (13).

- Calculation of Homeostasis model assessment of 及 cell function (HOMA-B): HOMA-B was calculated as follows: $20 \times$ fasting insulin $(\mu \mathrm{IU} / \mathrm{ml})$ / fasting glucose $(\mathrm{mmol} / \mathrm{ml})-3.5(14)$.

\section{Statistical analysis:}

Mean \pm SEM is the way by which data were expressed. SPSS (statistical program for social science) statistical package (SPSS Inc.) version 20 was used for statistical analysis. Significant differences in the same group were detected by paired " $\mathrm{t}$ " test, those between groups were detected by independent sample " $\mathrm{t}$ " test. Correlation study was done by using Pearson's correlation coefficient. Statistical significance was considered when $P$ value is $\leq 0.05$.

\section{Results:}

- Effect of MSG on body weight and number of off springs $\left(\mathrm{no}^{\circ}\right)$ :

Table (1) shows significant increase in final body weight (FBW) in both studied groups at the end of their lactation period compared to their initial pre pregnancy values, however, the FBW was insignificantly different between both groups. It was observed that the pregnancy belly size of MSG fed rats was more evident than their controls, ending up with a statistically significant higher number of off springs. 
Table (1): Mean \pm SEM values of initial body weight (IBW), final body weight (FBW) and number of off springs (no ${ }^{\circ}$ in the control and MSG groups.

\begin{tabular}{|l|c|c|c|}
\hline & IBW (g.) & FBW (g.) & no of off springs \\
\hline Control & $181.63 \pm 2.57$ & $234.5^{*} \pm 2.56$ & $5.2 \pm 0.74$ \\
\hline MSG & $184.25 \pm 3.78$ & $236.75^{*} \pm 2.48$ & $8.2^{\mathrm{a}} \pm 0.31$ \\
\hline
\end{tabular}

*: significance from their initial values calculated by student ${ }^{\prime} t$ test for paired data with $\mathrm{P} \leq 0.05$. a: Significance by independent sample " $\mathrm{t}$ " test from control group with $\mathrm{P} \leq 0.05$.
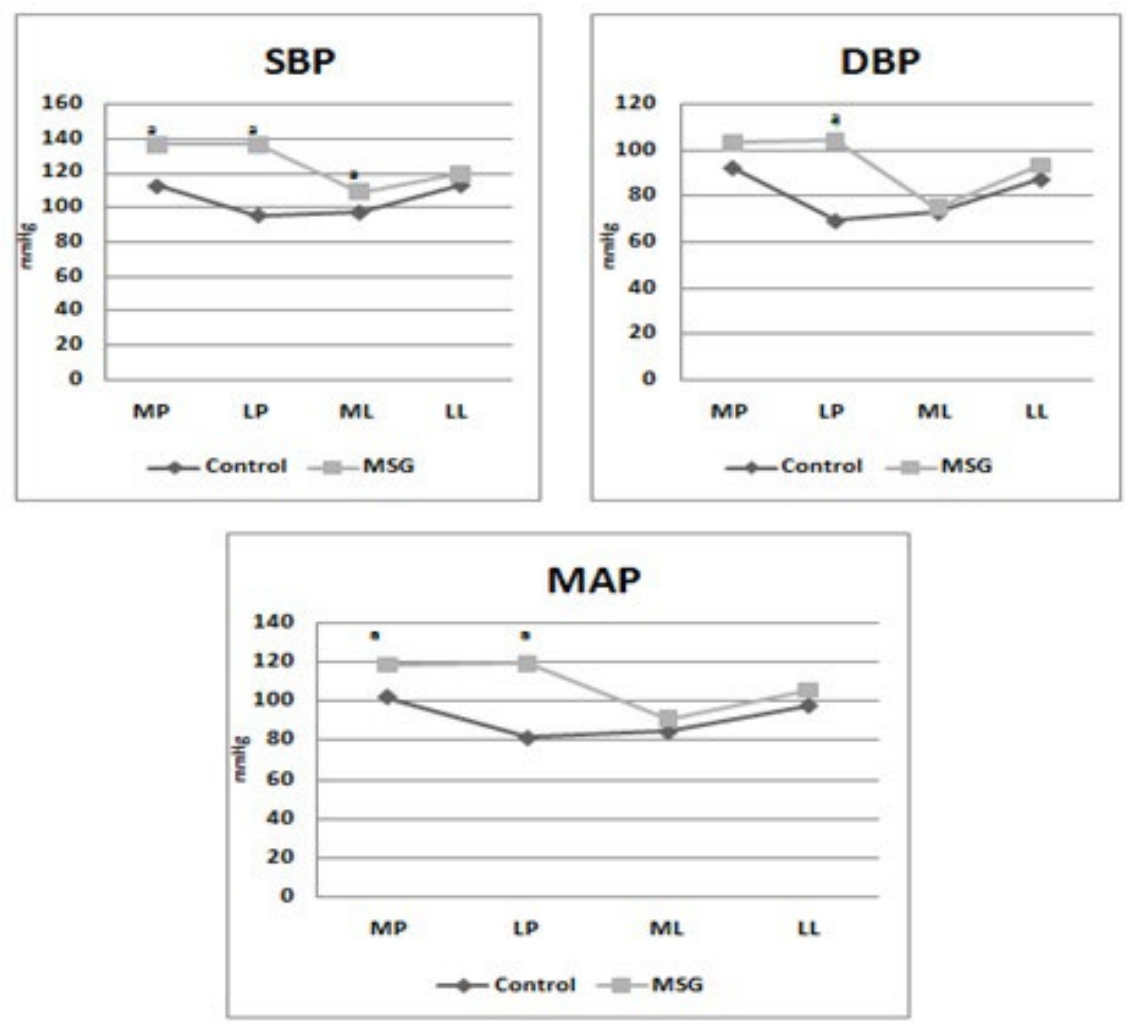

Figure (1): Systolic blood pressure (SBP), diastolic blood pressure (DBP) and mean arterial blood pressure (MAP) at mid and late pregnancy (MP, LP respectively) \& mid and late lactation (ML, LL respectively) periods in the control and MSG groups. a: Significance by independent sample " $t$ " test from control group with $\mathrm{P} \leq 0.05$.

\section{- Effect of MSG on arterial blood pressure:}

There was a significant elevation of systolic blood pressure (SBP) and mean arterial pressure (MAP) in the MSG pregnant rats at their mid pregnancy period compared to their controls, while at their late pregnancy, SBP, DBP and MAP were all significantly elevated. Only SBP was significantly elevated in the MSG rats during their mid lactation period, while the elevation in the late lactation period was insignificant compared to the control rats as shown in figure (1).

- Effect of MSG on oral glucose tolerance test (OGTT): The results of OGTT show insignificant differences between the 2 studied groups at fasting and all test times besides total area under the curve at mid and late pregnancy periods, while at both mid and late lactation periods, MSG fed rats showed significantly higher fasting glucose compared to the controls, in addition, they showed a significantly higher blood glucose at 90 min postprandial in the mid lactation period and at 120 min postprandial in the late lactation period compared to the control rats. AUC was significantly higher in MSG fed rats only at mid lactation, while other test times were non significantly higher than controls as shown in figure (2). 

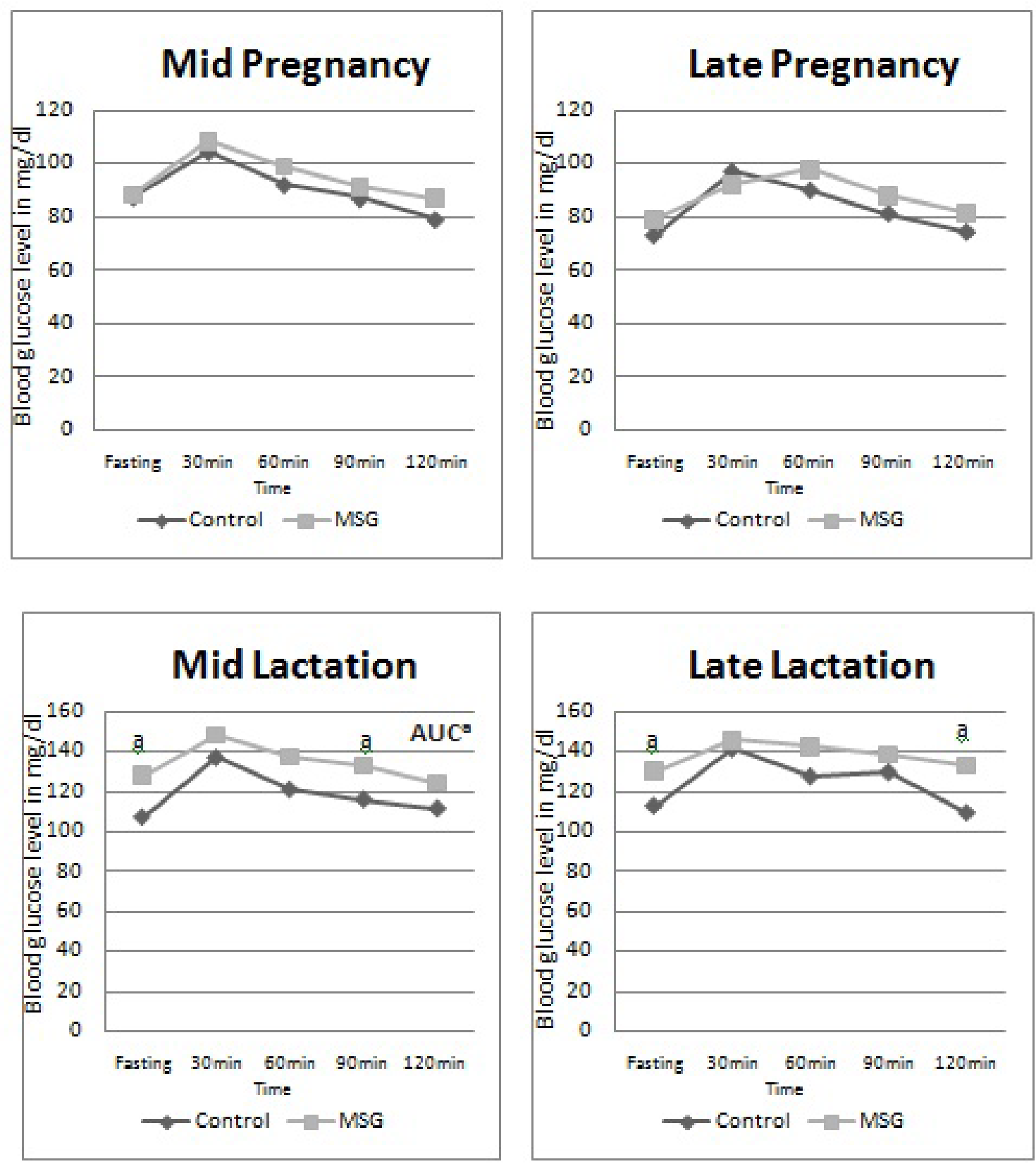

Figure (2): Oral glucose tolerance test (OGTT); fasting, 30, 60, 90, 120 minutes blood glucose level (mg/dl), and area under the curve (AUC) at mid and late pregnancy $\&$ mid and late lactation periods in the control and MSG groups .a: Significance by independent sample " $t$ " test from control group with $\mathrm{P} \leq 0.05$.

\section{- Effect of MSG on mid-lactation serum glucose and}

\section{pancreatic parameters:}

As shown in table (2), mid-lactation serum fasting glucose, glucagon, pancreatic amylase and lipase were significantly elevated in the MSG group compared to the controls, while fasting insulin level and calculated HOMA-B were significantly lower than controls. 
Table (2): Mean \pm SEM values of serum glucose, insulin, glucagon, pancreatic amylase, lipase, and HOMA-B at mid lactation period in the control and MSG groups.

\begin{tabular}{|c|c|c|c|c|c|c|}
\hline & $\begin{array}{c}\text { Glucose } \\
(\mathbf{m g} / \mathbf{d l})\end{array}$ & $\begin{array}{c}\text { Insulin } \\
(\mathbf{n g} / \mathbf{m l})\end{array}$ & $\begin{array}{c}\text { Glucagon } \\
\mathbf{( p g} / \mathbf{m l})\end{array}$ & $\begin{array}{c}\text { Pancreatic } \\
\text { amylase } \\
\mathbf{( U / m l )}\end{array}$ & $\begin{array}{c}\text { Pancreatic } \\
\text { lipase } \\
(\mathbf{U} / \mathbf{m l})\end{array}$ & HOMA-B \\
\hline Control & 106.11 & 2.56 & 5.47 & 415.29 & 242.84 & 502.90 \\
& \pm 4.06 & \pm 0.14 & \pm 0.44 & \pm 4.76 & \pm 11.38 & \pm 81.99 \\
\hline MSG & $133.05^{\mathbf{a}}$ & $1.27^{\mathbf{a}}$ & $20.61^{\mathbf{a}}$ & $706.60^{\mathbf{a}}$ & $485.16^{\mathbf{a}}$ & $150.09^{\mathbf{a}}$ \\
& \pm 8.38 & \pm 0.10 & \pm 1.12 & \pm 27.92 & \pm 25.01 & \pm 17.03 \\
\hline
\end{tabular}

a: Significance by independent sample " $\mathrm{t}$ " test from control group with $\mathrm{P} \leq 0.05$.

Table (3): Mean \pm SEM values of serum prolactin, corticosterone, and adrenocorticotropic hormone (ACTH) at mid lactation period in the control and MSG groups

\begin{tabular}{|l|c|c|c|}
\hline & $\begin{array}{c}\text { Prolactin } \\
(\mathbf{n g} / \mathbf{m l})\end{array}$ & $\begin{array}{c}\text { Corticosterone } \\
\mathbf{( n g} / \mathbf{m l})\end{array}$ & $\begin{array}{c}\text { ACTH } \\
\mathbf{( p g} / \mathbf{m l})\end{array}$ \\
\hline Control & 10.47 & 2.67 & 41.39 \\
& \pm 0.74 & \pm 0.14 & \pm 2.10 \\
\hline MSG & $37.83^{\mathrm{a}}$ & $9.02^{\mathrm{a}}$ & $18.68^{\mathrm{a}}$ \\
& \pm 2.55 & \pm 0.39 & \pm 1.14 \\
\hline
\end{tabular}

a: Significance by independent sample " $\mathrm{t}$ " test from control group with $\mathrm{P} \leq 0.05$.

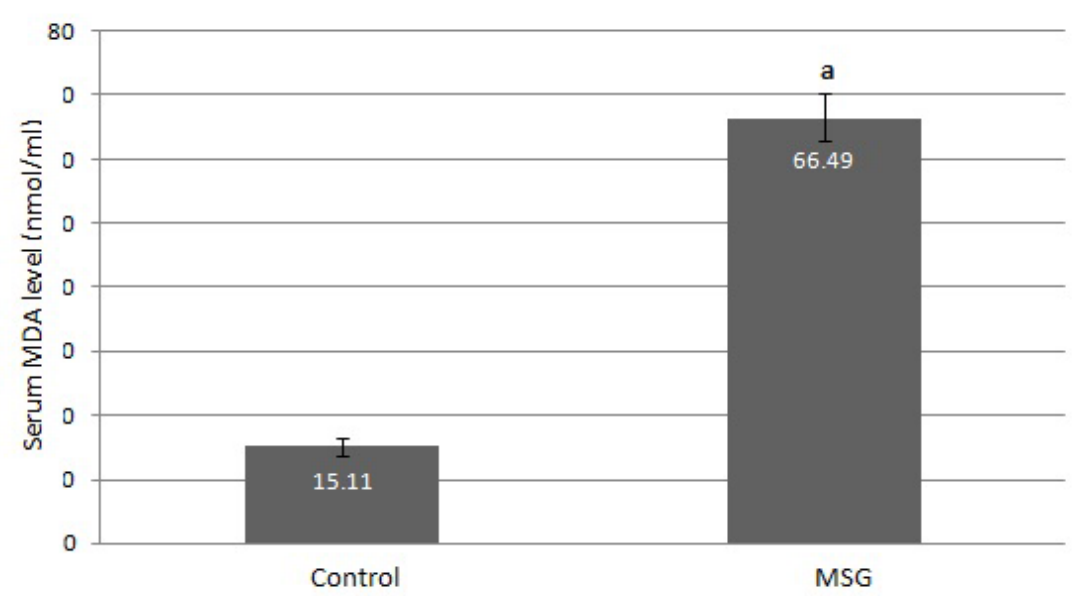

Figure (3): Serum malondialdehyde (MDA) level at mid lactation period in the control and MSG groups. a: Significance by independent sample " $\mathrm{t}$ " test from control group with $\mathrm{P} \leq 0.05$.

\section{- Effect of MSG on mid-lactation serum prolactin} and hypophyseal-adrenal axis:

Table (3) shows significantly higher serum prolactin and corticosterone, with significantly lower ACTH level in the MSG group compared to the controls.

- Effect of MSG on mid-lactation serum malondialdehyde (MDA): Figure (3) shows 
significantly higher serum MDA level in the MSG

group compared to the controls.

\section{- Effect of MSG on mid-lactation lipid profile:}

Table (4) shows significant elevation in triglycerides (TGs), total cholesterol (TC), low density lipoprotein cholesterol (LDL-C) and significant reduction in high density lipoprotein cholesterol (HDL-C) in the MSG group compared to the control group.

Table (4): Mean \pm SEM values of serum lipid profile at the mid lactation period in the control and MSG groups.

\begin{tabular}{|l|c|c|c|c|}
\hline & $\begin{array}{c}\text { TGs } \\
(\mathbf{m g} / \mathbf{d l})\end{array}$ & $\begin{array}{c}\text { TC } \\
(\mathbf{m g} / \mathbf{d l})\end{array}$ & $\begin{array}{c}\text { HDL-C } \\
\mathbf{( m g / d l})\end{array}$ & $\begin{array}{c}\text { LDL-C } \\
(\mathbf{m g} / \mathbf{d l})\end{array}$ \\
\hline Control & 110.48 & 139.04 & 57.26 & 59.68 \\
& \pm 3.57 & \pm 1.40 & \pm 0.61 & \pm 1.91 \\
\hline MSG & $162.73^{\mathrm{a}}$ & $245.13^{\mathrm{a}}$ & $33.83^{\mathrm{a}}$ & $178.754^{\mathrm{a}}$ \\
& \pm 2.93 & \pm 11.75 & \pm 1.60 & \pm 12.25 \\
\hline
\end{tabular}

a: Significance by independent sample " $t$ " test from control group with $\mathrm{P} \leq 0.05$.

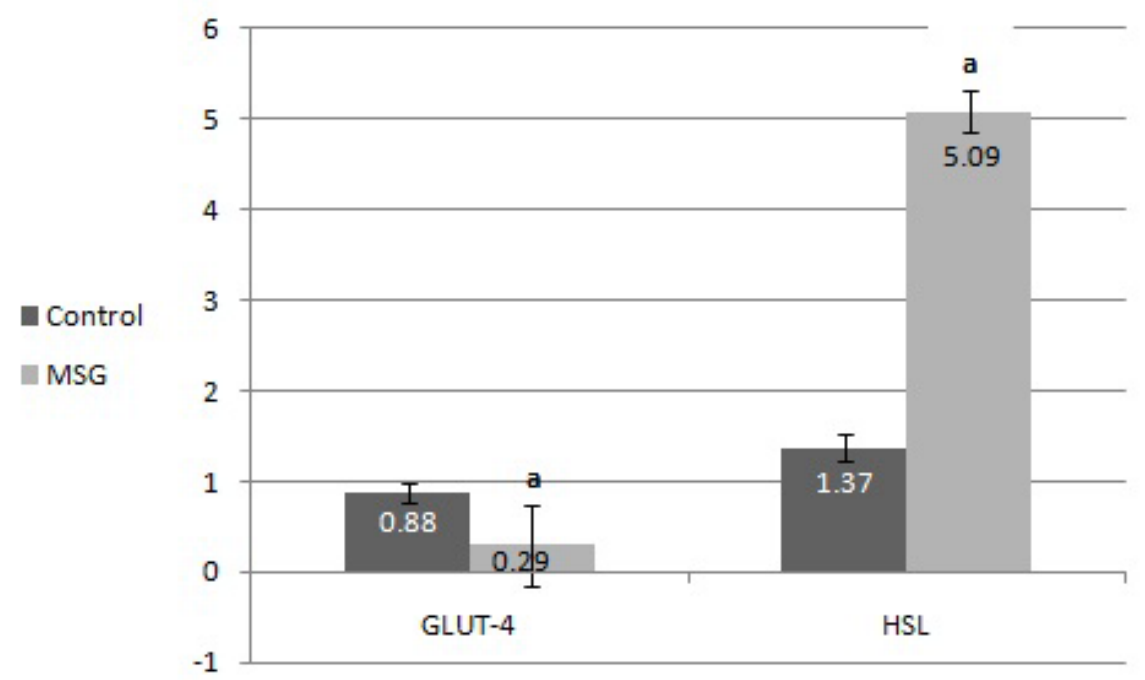

Figure (4): Relative expression of adipose tissue glucose transporter-4 (GLUT-4) and hormone sensitive lipase (HSL) at the end of lactation in the control and MSG groups. a: Significance by independent sample " $t$ " test from control group with $\mathrm{P} \leq 0.05$.

\section{- Effect of MSG on adipose tissue expression of}

\section{GLUT-4 and HSL at the end of lactation:}

The relative expression of adipose tissue GLUT-4 was significantly declined, while, HSL expression was significantly elevated in the MSG rats compared to their controls as shown in figure (4).

\section{Correlation study:}

A correlation study revealed, a significant negative association between serum insulin and total area under the curve (AUC) at mid lactation period $(r=-0.630$, $\mathrm{P}<$ 0.01). Also, significant positive correlation between each of glucagon, corticosterone, MDA and 
AUC at mid lactation period $(\mathrm{r}=0.595, \mathrm{P}<0.02), \mathrm{r}=$ 0.570, $\mathrm{P}<0.05),(\mathrm{r}=0.599, \mathrm{P}<0.02)$, respectively.

MDA showed a significant negative correlation with serum insulin $(r=-0.869, \mathrm{P}<0.001)$, HOMA-B $(\mathrm{r}=-0.703, \mathrm{P}<0.005)$, and a significant positive correlation with serum glucagon $(\mathrm{r}=0.947)$, corticosterone $(r=0.966)$, pancreatic amylase $(r=$ $0.881)$ and pancreatic lipase $(r=0.908)$, all at $\mathrm{P}<$ 0.001 .

Insulin showed a significant positive correlation with GLUT-4 $(r=0.602, \mathrm{P}<0.02)$ and a significant negative correlation with HSL $(\mathrm{r}=-0.839)$. Glucagon, corticosterone, MDA showed significant positive correlation with HSL $(r=0.891),(r=0.945),(r=$ 0.926), respectively, all at $\mathrm{P}<0.001$.

\section{Discussion:}

The European Food Safety Association (EFSA) Panel on Food Additives and Nutrient Sources Added to Food(15) re-evaluated MSG and decided that daily intake of $30 \mathrm{mg} / \mathrm{kg}$ body weight of monosodium glutamate (MSG) is agreeable.

In the present study, $2 \%$ MSG by weight was added to the standard rat chow, turning it more palatable, rats used to consume the entire amount provided, which could be considered an average dose compared to other studies and could be truly consumed through diet.

Many studies on both animals and humans, have correlated the use of MSG with the induction of obesity and metabolic syndrome (16), due to its direct actions in the brain affecting food intake (17). In this study, administration of MSG supplemented diet starting about 1 week prior and throughout the whole pregnancy and lactation (approx. 42 days) in rats didn't induce a significant change in their final body weight compared to the controls, this was demonstrated earlier by Bunyan et al. (18), whose female rodents body weight was not increased significantly after MSG treatment, unlike males that showed significant increase in body and epididymal fat pad weights. Also, after 40 days of feeding rats with $1 \mathrm{mg}$ MSG/g of feed, there was no significant difference in food intake, final body weight or perigonadal fat depots(19), on the other hand, Kondoh and Torii (20) reported a negative correlation between MSG and body weight.

Concerning the observed number of offsprings, the present study showed there were significantly increased in MSG fed rats compared to controls, this is in contrary to Nnadozie et al. (21) who reported a decline in fertility in rats on MSG than in controls (48 versus 117 births respectively). In the same context, Eweka and Om'Iniabohs (22) stated that MSG might have harmful effects on the ovarian oocytes of adult Wistar rats and might participate in female infertility. Also, Mondal et al. (23) suggested that MSG might prohibit reproductive functions in females by impairing the ovarian functions.

SBP and MAP were significantly elevated in the MSG pregnant rats at their mid pregnancy period compared to controls, while at late pregnancy, DBP was also significantly elevated. A large cross-sectional study concluded that MSG intake was strongly accompanied with a significant increase in SBP and DBP (24). In addition, Wang et al. (10) reported that MSG could induce hypertension in pregnant rats possibly through vascular endothelial injury and central neuronal damage.

In our study, blood pressure was ameliorated during the lactation period and became insignificant from controls at late lactation 
despite longer period of MSG supplementation, this could be in accordance with a study by Countouris et al.(25) who reported that lactating women after suffering gestational hypertension were presented with lower blood pressure, moreover, Burgess et al.(26) demonstrated a significant difference in both SBP and DBP at the initial postpartum visit between lactating and nonlactating women with preeclampsia, with strong recommendation of breast feeding in those had preeclampsia.

In a neonatal rat model, induction of obesity using MSG was associated with slight elevation in MAP compared to controls with reduced baroreflex sensitivity, involving both vagus and sympathetic limbs indicating autonomic dysfunction (27).

In the current study, OGTT showed insignificant changes between the studied groups throughout their pregnancy, however impaired glucose tolerance was detected in their mid and late lactation period demonstrated by impaired fasting and late postprandial times (at $90 \& 120$ min). This could be explained by the associated mid lactation significantly decreased insulin and significantly increased glucagon, corticosterone and MDA, that was moreover, supported by the correlation study.

In a study investigating the effect of daily MSG dietary consumption of $2 \mathrm{mg} / \mathrm{g}$. B.W. for different durations, the authors revealed reduction in pancreatic $\beta$-cell mass with evident hemorrhages and fibrosis without affecting glucose homeostasis (serum insulin and OGTT) at all studied periods, from 1 month to 9 months of MSG consumption by rats (28). Another study demonstrated reduction in muscarinic type-3 receptor/protein kinase $\mathrm{C}(\mathrm{PKC})$ and adenylate cyclase/protein kinase A (PKA) activation of the pancreatic $\beta$-cell, increasing liability of its dysfunction in rats treated with subcutaneous injection of MSG (29).

However, it was reported that rats received MSG in drinking water showed non-significant differences in serum insulin levels and glucose tolerance when compared with controls at all investigated times despite B cell affection (28).

In addition, there is evidence of pancreatic insult in the MSG fed rats, the pancreatic amylase and lipase were significantly higher compared to the controls. Abdulsalam et al. (30) suggested that MSG caused changes in the plasma of lipase and amylase activities, possibly due to structural and chemical changes in the pancreatic acini resulting in leakage of enzymes into the circulation. Besides significantly lower fasting insulin level after MSG feeding, which might suggest pancreatic B cell affection in these rats, however, a significant higher glucagon level, excludes pancreatic alpha cell insult, on the contrary, their secretion was increased which could be due to diminished insulin inhibitory effect. Also, hyperglucagonemia, hyperglycemia, hyperinsulinemia with obesity were reported in 90 days old mice after neonatal subcutaneous injection of MSG, in addition to $\alpha$ cells hypertrophy with increased phosphorylated mammalian target of rapamycin (pmTOR) protein immunoreactivity (31).

These significant changes in fasting insulin and glucagon, as well as, increased corticosterone, could be the cause of MSG fed rats fasting hyperglycemia, that was significantly higher than controls at the mid lactation period.

Munoz et al. (32) studied pregnant rats throughout pregnancy period, the results revealed 
that there is an enhanced glucose induced insulin release with reduced insulin sensitivity in 12th day pregnant rats indicating insulin resistance, but, at 15th day pregnancy both beta-cell response and insulin sensitivity return to non-pregnant values.

Upon performing glucose tolerance test in MSG fed rats by Hirata et al.(33), the fasting blood glucose level was non-significantly changed from controls, however, after the glucose load, impaired glucose tolerance was pointed out by the hyperglycemia in MSG fed rats at minute 4 and from minute 16 to minute 32 .

Also, Oriaghan et al. (34) showed that weekly follow up of blood glucose concentrations revealed its significant elevation in MSG fed animals suggesting the potential of MSG to induce hyperglycemia and consequently diabetes mellitus.

On the other hand, a cohort study on Chinese adults demonstrated that increased MSG administration lead to decreased risk of hyperglycemia (35).

Moreover, adipose tissue GLUT-4 expression was significantly decreased in the MSG fed rats compared to their controls, this finding could be attributed to the insulin deficiency demonstrated in those rats as proved by a significant positive correlation, this is similar to Machado et al.(36), whose MSG-treated mice showed a decrease of 50\% in GLUT-4 expressed on white adipose tissue from all membrane fractions.

In the present study, the MSG fed rats demonstrated high lipid profile parameters compared to controls in spite of insignificant BW changes, this could be in accordance to Afifi and Abbas(37) who compared MSG fed to high caloric diet fed rats and observed lower daily food consumption and BW in MSG treated rats than those of high caloric diet fed rats, however, their absolute and relative visceral fat weight were higher, but both models showed increased $\mathrm{Ob}$ gene expression, hyperleptinemia, hyperinsulinemia, hyperglycemia and dyslipidemia.

In our study, adipose tissue hormone sensitive lipase (HSL) relative expression was significantly enhanced in MSG fed rats, indicating a state of fat depot breakdown, this goes with the significant decline in the hormonal serum levels of insulin which decreased its inhibitory effect on HSL, this was further proved by the correlation study. Concerning the changes of HSL in pregnancy and lactation, Martin-Hidalgo et al.(38) reported that HSL activity and expression was elevated at days 12-15 of pregnancy then reduced to control levels after delivery, while the ratio of HSL-to-lipoprotein lipase (LPL) expression and activity were increased at late pregnancy, and remained so even during lactation, due to marked decrease of the LPL level. This increment was associated with higher levels of plasma FFA and glycerol levels denoting increased adipolysis. Also, Araujo et al. (31) reported increased white fat content of phosphorylated HSL on MSG neonatal administration.

On the contrary to our study, Dolnikoff et al.(39) observed that both the HSL expression and activity were lower in adipose tissue after neonatal administration of MSG to rats leading to decreased lipolytic activity, with increased number of insulin receptors and GLUT-4 translocation resulting in enhanced glucose uptake, the authors proposed an enhanced insulin sensitivity.

In this study, serum Malondialdehyde was significantly elevated in MSG fed rats denoting 
oxidative stress, this could be in accordance to Diniz et al.(4), who also added MSG to a standard diet which induced overfeeding, hyperglycemia and dyslipidemia in the absence of obesity, the authors attributed these adverse effects to oxidant and antioxidant imbalance. Onyema et al. (40) reported significant increase in lipid peroxidation and antioxidant enzymes activities in MSG administrated rats which confirm the oxidative damage induced by the excessive unbalanced production of reactive oxygen species. Oxidative stress might be the cause of the pancreatic insult as confirmed by the significant negative correlation between MDA and each of insulin and HOMA-B, in addition to the significant positive correlation between MDA and each of pancreatic amylase and lipase.

It was reported that oral route of administration of MSG is unlikely to cause alterations in the brain (41), only the nervous structures not protected by the $\mathrm{BBB}$, such as the circumventricular organs, could be vulnerable to MSG hazardus effect(42).

Glutamate was known to activate the hypothalamic pituitary axis, elevating ACTH (43). However, In this study, corticosterone was significantly increased in the MSG fed rats, whereas ACTH was significantly decreased, which indicates an adrenal gland affection by MSG that increased corticosterone secretion and exerted an inhibitory effect on ACTH, this could be in accordance to El-Helbawy et al.(44) who reported an increased thickness and secretion of the zona fasiculata by histopathology, and that these changes were reversible. Therefore, it could be concluded that it is adrenal gland rather than hypothalamic affection.
In the same context, prolactin level was significantly higher in MSG fed rats, this could be attributed to reduced prolactin elimination as a result of impaired liver and kidney functions rather than central affection, this impairment could be due to MSG-induced hepatorenal oxidative damage $(45,46)$, as MSG couldn't reach the tuberoinfundibular dopaminergic neurons projecting from arcuate nucleus regulating the secretion of prolactin from the anterior pituitary (47).

\section{Conclusion:}

MSG daily consumption by female rats during gestation and lactation periods resulted in metabolic derangements in glucose homeostasis, lipid metabolism and pancreatic function probably due to oxidative stress, it also elevated the ABP and increased corticosterone and prolactin.

\section{Conflict of interest:}

The authors declared no conflict of interest in this study.

\section{References:}

1. Hermanussen M, Garcia AP, Sunder M, Voigt M, Salazar V, Tresguerres JA. Obesity, voracity, and short stature: the impact of glutamate on the regulation of appetite. Eur. J. Clin. Nutr.; 60(1):25-31, 2006.

2. López-Miranda V, Soto-Montenegro ML, Uranga-Ocio JA, Vera G, Herradón E, González C, Blas C, MartínezVillaluenga M, López-Pérez AE, Desco M, Abalo R. Effects of chronic dietary exposure to monosodium glutamate on feeding behavior, adiposity, gastrointestinal motility, and cardiovascular function in 
healthy adult rats.Neurogastroenterol. Motil.; 27(11):1559-1570, 2015.

3. Kazmi Z, Fatima I, Perveen S, Malik SS. Monosodium glutamate: Review on clinical reports. International Journal of Food Properties; 20(5), 2017.

4. Diniz YS, Faine LA, Galhardi CM, Rodrigues HG, Ebaid GX, Burneiko RC, Cicogna AC, Novelli EL. Monosodium glutamate in standard and high-fiber diets: metabolic syndrome and oxidative stress in rats. Nutrition; 21(6):749$755,2005$.

5. Liang Q, Zhong L, Zhang J, Wang $\mathrm{Y}$, Bornstein SR, Triggle CR, Ding H, Lam KS, Xu A. FGF21 maintains glucose homeostasis by mediating the cross talk between liver and brain during prolonged fasting. Diabetes; 63(12):4064-4075, 2014.

6. Sahu A. Minireview: A hypothalamic role in energy balance with special emphasis on leptin. Endocrinology; 145(6):2613-2620, 2004.

7. Leshchenko IV, Shevchuk VH, Falalieieva TM, Beregova TV. The influence of longterm monosodium glutamate feeding on the structure of rats pancreas. Fiziol. Zh.; 58(2):59-65, 2012.

8. Damm P, Houshmand-Oeregaard A, Kelstrup L, Lauenborg J, Mathiesen ER, Clausen TD. Gestational diabetes mellitus and long-term consequences for mother and offspring: a view from Denmark. Diabetologia; 59(7): 1396-1399, 2016.

9. Naderi S, Tsai SA, Khandelwal A. Hypertensive disorders of pregnancy. Curr. Atheroscler. Rep.; 19 (3):15, 2017.

10. Wang J, Li J, Chen H, Dong YZ, Zhang LJ, Ge J. Study of animal model of hypertensive disorder complicating pregnancy in pregnant rats stimulated by homocysteine and monosodium glutamate. Zhonghua Fu Chan Ke Za Zhi; 42(5):330$333,2007$.

11. Boutry C, Bos C, Matsumoto H, Even P, Azzout-Marniche D, Tome D, Blachier F. Effects of monosodium glutamate supplementation on glutamine metabolism in adult rats. Front. Biosci.;3:279-90, 2011.

12. Friedewald WT, Levy RI, Frederickson DS. Estimation of the concentration of lowdensity lipoprotein cholesterol in plasma, without use of the preparative ultracentrifuge. Clin. Chem.; 18(6): 499 $502,1972$.

13. Matthews JN, Altman DG, Campbell MJ, Royston P. Analysis of serial measurements in medical research. BMJ; 300(6719):230235,1990

14. Wallace TM, Levy JC, Matthews DR. Use and abuse of HOMA modeling. Diabetes Care; 27(6):1487-1495, 2004.

15. EFSA Panel on Food Additives and Nutrient Sources Added to Food, (ANS), Mortensen A, Aguilar F, Crebelli R, Di Domenico A, Dusemund B, Frutos MJ, Galtier P, Gott D, Gundert-Remy U, Leblanc J, Lindtner O, Moldeus $\mathbf{P}$, Mosesso P, Parent-Massin D, Oskarsson A, Stankovic I, Waalkens-Berendsen I, Woutersen RA, Wright M, Younes M, Boon P, Chrysafidis D, G€urtler R, 
Tobback P, Altieri A, Rincon AM, Lambr

C. Re-evaluation of glutamic acid (E620), sodium glutamate; (E621), potassium glutamate (E622), calcium glutamate; (E623), ammonium glutamate (E624) and magnesium; glutamate (E625) as food additives. EFSA Journal; 15(7): e04910, 2017.

16. Brosnan JT, Drewnowski A, Friedman MI. Is there a relationship between dietary MSG and obesity in animals or humans?. Amino Acids; 46(9): 2075-2087, 2014.

17. Di Sebastiano KM, Bell KE, Barnes T, Weeraratne A, Premji T, Mourtzakis M. Glutamate supplementation is associated with improved glucose metabolism following carbohydrate ingestion in healthy males. Br. J. Nutr.; 110(12): 2165-2172, 2013.

18. Bunyan J, Murrell EA, Shah PP. The induction of obesity in rodents by means of monosodium glutamate. Br. J. Nutr.;35(1):25-39, 1976.

19. Olguin MC, Posadas MD, Revelant GC, Marinozzi D, Labourdette V, Venezia MR. Monosodium Glutamate Affects Metabolic Syndrome Risk Factors on Obese Adult Rats: A Preliminary Study. J. Obes. Weight-loss Medic.; 4 (1): 023, 2018.

20. Kondoh $\mathbf{T}$ and Torii K. MSG intake suppresses weight gain, fat deposition, and plasma leptin levels in male SpragueDawley rats. Physiol. Behav.; 95(1-2): 135144, 2008.

\footnotetext{
21. Nnadozie JO, Chijioke UO, Okafor OC, Olusina DB, Oli AN, Nwonu PC, Mbagwu HO, Chijioke CP. Chronic
}

toxicity of low dose monosodium glutamate in albino Wistar rats. BMC Res. Notes; 12(1):593, 2019.

22. Eweka AO and Om'Iniabohs FAE. Histological Studies of the Effects of Monosodium Glutamate on the Ovaries of Adult Wistar Rats. Ann. Med. Health Sci. Res.; 1(1): 37-43, 2011.

23. Mondal M, Sarkar K, Nath PP, Paul G. Monosodium glutamate suppresses the female reproductive function by impairing the functions of ovary and uterus in rat. Environ. Toxicol.;33(2):198-208, 2018.

24. Shi Z, Yuan B, Taylor AW, Dai Y, Pan X, Gill TK, Wittert GA. Monosodium glutamate is related to a higher increase in blood pressure over 5 years: findings from the Jiangsu Nutrition Study of Chinese adults. J. Hypertens.; 29(5):846-853, 2011.

25. Countouris ME, Schwarz EB, Rossiter BC, Althouse AD, Berlacher KL, Jeyabalan A, Catov JM. Effects of lactation on postpartum blood pressure among women with gestational hypertension and preeclampsia. Am. J. Obstet. Gynecol.; 215(2):241.e1-8, 2016.

26. Burgess A, McDowell W, Ebersold S. Association between Lactation and Postpartum Blood Pressure in Women with Preeclampsia. MCN Am. J. Matern. Child. Nurs.;44(2):86-93, 2019.

27. Konrad SP, Farah V, Rodrigues B, Wichi RB, Machado UF, Lopes HF, D'Agord Schaan B, De Angelis K, Irigoyen MC. Monosodium glutamate neonatal treatment induces cardiovascular autonomic function 
changes in rodents. Clinics; 67(10): 12091214, 2012.

28. Boonnate P, Waraasawapati S, Hipkaeo W, Pethlert S, Sharma A, Selmi C, Prasongwattana V, Cha'on U. Monosodium Glutamate Dietary Consumption Decreases Pancreatic $\beta$-Cell Mass in Adult Wistar Rats. PLoS One; 29; 10(6):e0131595, 2015.

29. Ribeiro RA, Balbo SL, Roma LP, Camargo RL, Barella LF, Vanzela EC, de Freitas Mathias PC, Carneiro EM, Boschero AC, Bonfleur ML. Impaired muscarinic type 3 (M3) receptor/PKC and PKA pathways in islets from MSG-obese rats. Mol. Biol. Rep.; 40 (7): 4521-4528, 2013.

30. Abdulsalam H, Adamu S, Sambo SJ, Chiroma MA, Gadzama JJ, Mohzo DL, Atata JA. Monosodium glutamate-induced changes on plasma markers of pancreatic function in adult male Wistar rats. Sokoto Journal of Veterinary Sciences; 16(2): 2127, 2018.

31. Araujo TR, da Silva JA, Vettorazzi JF, Freitas IN, Lubaczeuski C, Magalhães EA, Silva JN, Ribeiro ES, Boschero AC, Carneiro EM, Bonfleur ML, Ribeiro RA. Glucose intolerance in monosodium glutamate obesity is linked to hyperglucagonemia and insulin resistance in $\alpha$ cells. J. Cell Physiol.; 234(5):70197031,2019 .

32. Muñoz C, López-Luna P, Herrera E. Glucose and insulin tolerance tests in the rat on different days of gestation. Biol. Neonate;68(4):282-291, 1995.
33. Hirata AE, Andrade LS, Vaskevicius P, Dolnikoff MS. Monosodium glutamate (MSG)-obese rats develop glucose intolerance and insulin resistance to peripheral glucose uptake. Braz. J. Med. Biol. Res.; 30 (5) 671-674, 1997.

34. Oriaghan EA, Inegbenebor V, Shelu OJ, Obhimon O, Idonor EO, Ekhoye I. The effect of monosodium glutamate (MSG) on blood glucose in adult rabbits as models. International Journal of Basic, Applied and Innovative Research; 1(1), 2012.

35. Shi Z, Taylor AW, Yuan B, Zuo H, Wittert GA. Monosodium glutamate intake is inversely related to the risk of hyperglycemia. Clin. Nutr.; 33(5):823-828, 2014.

36. Machado UF, Shimizu Y, Saito M. Decreased glucose transporter (GLUT 4) content in insulin-sensitive tissues of obese aurothioglucose

and monosodium glutamate-treated mice. Horm. Metab. Res.; 25(9):462-465, 1993.

37. Afifi MM and Abbas AM. Monosodium glutamate versus diet induced obesity in pregnant rats and their offspring. Acta. Physiol. Hung.; 98(2):177-88, 2011.

38. Martin-Hidalgo A, Holm C, Belfrage P, Schotz MC, Herrera E. Lipoprotein lipase and hormone-sensitive lipase activity and mRNA in rat adipose tissue during pregnancy. Am. J. Physiol.;266(6 Pt 1):E930-935, 1994.

39. Dolnikoff M, Martín-Hidalgo A, Machado UF, Lima FB, Herrera E. Decreased lipolysis and enhanced glycerol and glucose utilization by adipose tissue prior to 
development of obesity in monosodium glutamate (MSG) treated-rats. Int. J. Obes. Relat. Metab. Disord.; 25(3):426-433, 2001.

40.

Onyema OO, Farombi EO, Emerole GO,

Ukoha AI, Onyeze GO. Effect of Vitamin

$\mathrm{E}$ on Monosodium Glutamate Induced Hepatotoxicity and Oxidative Stress in Rats. Indian J. Biochem. Biophys.; 43(1): 20-24, 2006.

41. Henry-Unaeze HN. Update on food safety of monosodium l-glutamate

(MSG). Pathophysiology; 24 (4): 243-249, 2017.

42. Smith QR. Transport of glutamate and other amino acids at the blood-brain barrier. J. Nutr.; 130 (4S Suppl): 1016S-1022S, 2000.

43. Zelena D, Mergl Z, Makara GB. Glutamate agonists activate the hypothalamic-pituitaryadrenal axis through hypothalamic paraventricular nucleus but not through vasopressinergic neurons. Brain Res.; 1031(2):185-193, 2005.

44. El-Helbawy NF, Radwan DA, Salem MF, El-Sawaf ME. Effect of monosodium glutamate on body weight and the histological structure of the zona fasciculata of the adrenal cortex in young male albino rats. Tanta medical journal; 45 (2): 104-113, 2017.

45. Paul MV, Abhilash M, Varghese MV, Alex M, Nair RH. Protective effects of $\alpha$ tocopherol against oxidative stress related to nephrotoxicity by monosodium glutamate in rats. Toxicol. Mech. Methods; 22(8):625630, 2012.

46. Eweka AO, Igbigbi PS, Ucheya RE. Histochemical Studies of the Effects of Monosodium Glutamate on the Liver of Adult Wistar Rats. Ann. Med. Health Sci. Res.; 1(1): 21-29, 2011.

47. Bogdanov MB, Tjurmina OA, Wurtman RJ. Consumption of a high dietary dose of monosodium glutamate fails to affect extracellular glutamate levels in the hypothalamic arcuate nucleus of adult rats. Brain Res.; 736:76-81, 1996. 